\title{
Cultivares e estádios de Colheita no Rendimento Forrageiro da Soja
}

\author{
Pedro Milanez de Rezende, UFLA, pmrezend@dag.ufla.br \\ Cristiane Fortes Gris, IFSULDEMINAS, cristianegris@eafmuz.gov.br \\ Alexandre Martins Abdão dos Passos, UFLA, aabdao@terra.com.br \\ Antônio Ricardo Evangelista, UFLA, aricardo@ufla.br \\ Élberis Pereira Botrel, UFLA, elberis@ufla.br
}

\section{RESUMO}

Com o objetivo de verificar a influência do estádio de colheita sobre a produção e a qualidade do feno de duas cultivares de soja foi conduzido ensaio em Lavras, MG, no ano agrícola 2001/02. Utilizou-se o delineamento experimental de blocos casualizados, em esquema fatorial 2 x 5, com três repetições, compreendendo duas cultivares (Conquista e Monsoy 8400) e cinco estádios de corte (R2, R3, R4, R5 e R6). As cultivares afetaram apenas o rendimento de proteína do feno. Os maiores rendimentos de matéria seca, feno e proteínas foram obtidos com os cortes nos estádios R4, R5 e R6. Quanto ao rendimento de proteína bruta, verificou-se queda após o corte em R5. Esta redução, provavelmente, associada a efeito de estresse hídrico e ou diluição da proteína na matéria seca. O estádio de desenvolvimento R4 apresentou a melhor opção de corte para fenação, independentemente da cultivar. A cultivar Monsoy 8400 apresentou maior rendimento de proteína bruta que a cultivar Conquista.

Palavras-chave: feno, proteína, épocas, matéria seca, produtividade.

\section{Cultivars and Cutting Time in the Yield of the Soybean Forage}

\begin{abstract}
This study aimed to evaluate the influence of different genotypes and cutting periods on the yield and quality of soybean hay. The experiment was carried out on the agricultural year of 2001/02 at the experimental area of UFLA (University of Lavras), Lavras, MG. The experiment was arranged in randomized blocks design, in a factorial scheme (5X3) with three replicates, understanding two cultivars (Conquista and Monsoy 8400) and five cutting periods (phenological stages R2, R3, R4, R5 and R6). The different cultivars influenced just the crude protein yield. The biggest dry matter, hay and crude protein yields were reached on phonological stages R4, R5 and R6. Was verified that the crude protein yield decreased from the stage R5 to R6. That could be associated to the dilution effect in the dry matter and to a hydric stress. It is inferred that the stage of development R4 is the best cutting period option for hay, concerning the quality of the hay. The cultivar Monsoy 8400 presents, in relation to Conquista, the best option for production of the hay.
\end{abstract}

Key words: hay, protein, cutting times, dry matter, yield. 


\section{INTRODUÇ̃̃O}

A soja é atualmente uma das espécies mais cultivadas no Brasil, sendo a produção de grãos, a sua forma mais utilizada, tanto na alimentação animal como no consumo humano. Por outro lado, a utilização desta oleaginosa para forragem tem sido pouco difundi$\mathrm{da}$, apesar da alta qualidade nutritiva e de seu excelente potencial de produção.

$\mathrm{Na}$ região Sul de Minas Gerais, caracterizada como importante bacia leiteira do país, o uso da soja está voltado para alimentação do rebanho leiteiro, principalmente na forma de farelo, utilizado como fonte de proteína na composição de rações comerciais, o que onera bastante o custo de produção das mesmas. Uma alternativa para reduzir custos e gerar benefícios econômicos, é o cultivo da soja, na propriedade, para ser utilizada tanto na forma de grãos, feno, silagem ou rolão (Rezende et al., 2003; Gris et al., 2008).

Pesquisas sobre a utilização da soja, na forma de feno, têm sido realizadas visando determinar cultivares apropriadas e o estádio fenológico em que a planta apresenta maior valor protéico para ser fornecida ao animal. Segundo Santos \& Vieira (1982), a parte aérea da planta, quando cortada até o estádio V13 e fenada, tem aproximadamente o mesmo valor nutritivo de outras leguminosas forrageiras de alta qualidade, como a alfafa e a soja perene.

Estudos avaliando desempenho de genótipos para obtenção de feno são de suma importância, haja vista que diversos autores tem evidenciado comportamento diferencial de cultivares de soja quanto ao rendimento e qualidade do feno obtido (Rezende et al., 1997a; Botrel \& Rezende, 1999; Rezende et al., 2001a; Rezende et al., 2003).

Munoz et al. (1983) relatam que, para se manter o balanço ideal entre o rendimento e a qualidade do feno, o corte deve ser realizado nas fases de formação e enchimento de legumes. Rezende et al. (2001) trabalhando com a cultivar Cristalina, em diferentes estádios de colheita, determinaram que os rendimentos de massa verde, feno, matéria seca e qualidade de feno obtidos, se elevaram à medida que se retardou o corte. Botrel et al. (2003) comparando as cultivares Cristalina e Doko observaram resposta superior da cultivar Doko nos rendimentos médios de matéria seca e proteína bruta total.

Portanto, a necessidade de maiores informações sobre a utilização da soja para fenação representa ainda uma grande demanda do setor pecuário, sobretudo no que diz respeito às recomendações de cultivares, bem como estádio ideal de colheita. Dentro deste contexto, objetivou-se com esse trabalho avaliar cultivares e estádios de colheita no rendimento forrageiro da soja [Glycine max (L) Merrill].

\section{MATERIAL E MÉTODOS}

O ensaio foi conduzido no Campus Experimental da Universidade Federal de Lavras - UFLA, município de Lavras (MG), situado a $21^{\circ} 14^{\prime}$ de latitude Sul, $45^{\circ} 00^{\prime}$ de longitude Oeste e $918 \mathrm{~m}$ de altitude, em solo classificado como Latossolo Vermelho Férrico (LVf) Distroférrico, de origem basáltica, com textura argilosa (55\% de argila), fase cerrado, que apresentou as seguintes características: $\mathrm{pH}$ em água 5,$8 ; \mathrm{Al}^{+3}$ trocável $=0,3$ cmol dm ${ }^{-3} ; \mathrm{Ca}^{+2}=2,2 \mathrm{cmol}_{\mathrm{c}} \mathrm{dm}^{-3} ; \mathrm{Mg}^{+2}=0,5$ $\mathrm{cmol}_{\mathrm{c}} \mathrm{dm}^{-3} ; \mathrm{K}^{+}=77 \mathrm{mg} \mathrm{dm}^{-3} ; \mathrm{P}=7,2 \mathrm{mg} \mathrm{dm}^{-3}$.

A região é caracterizada, segundo a classificação internacional de Köppen, de clima do tipo Cwa, temperado chuvoso (mesotérmico) e subtropical de inverno seco, tendo uma precipitação pluviométrica média no mês mais seco de $23,4 \mathrm{~mm}$ e de $295,8 \mathrm{~mm}$ no mês mais chuvoso. A temperatura média é de $22,1^{\circ} \mathrm{C}$ no mês mais quente e de $15,8^{\circ} \mathrm{C}$, no mês mais frio. A precipitação média anual é de 1529,7 mm, segundo Dantas (2007).

A adubação de semeadura foi feita de acordo com a análise de solo, seguindo as 
recomendações de Ribeiro et al. (1999), utilizando-se $400 \mathrm{~kg} \mathrm{ha}^{-1}$ do formulado 04-30-10. As sementes de soja foram inoculadas antes da semeadura com Bradyrhizobium japonicum, utilizando o inoculante turfoso na proporção de 600.000 bactérias por semente. Todos os tratamentos receberam sempre que necessário os tratos culturais indispensáveis à cultura.

O delineamento experimental foi o de blocos casualizados com três repetições em esquema fatorial $2 \times 5$, compreendendo duas cultivares de soja de alta representatividade para a sojicultura nacional, Conquista e Monsoy 8400 , e cinco estádios fenológicos R2, R3, R4, R5, e R6, compreendendo as fases de pleno florescimento, início da frutificação, legumes completamente desenvolvidos, início do enchimento dos grãos e granação completa dos grãos, respectivamente, Fehr \& Caviness 1977.

O ensaio foi instalado em Dezembro de 2001 em parcelas constituídas de quatro fileiras de $5,0 \mathrm{~m}$, espaçadas de $0,5 \mathrm{~m}$, mantendo densidade de 25 plantas por metro, sendo avaliadas como parcela útil as duas fileiras internas (200 plantas por parcela útil), excluindo-se $0,50 \mathrm{~m}$ das extremidades, a titulo de bordadura. Os cortes foram realizados rente ao solo, com o auxílio de uma roçadora costal motorizada.

Por ocasião dos cortes, , as seguintes características: rendimento de massa verde e matéria seca (secagem em estufa a $65^{\circ} \mathrm{C}$ com circulação de ar forçado), rendimento feno (considerando-se $15 \%$ de umidade) e rendimento proteína bruta (destilação a vapor pelo método micro-Kjeldahl). Os dados foram, posteriormente, convertidos em kg.ha-1 .

As análises de variância, para todas as características avaliadas, foram realizadas no programa estatístico SISVAR $\square$, segundo Ferreira (2008)s médias, quando significativas pelo teste de $\mathrm{F}$, comparadas pelo teste de Scott-Knott, a 5\% de probabilidade.

\section{RESULTADOS E DISCUSSÃO}

Os estádios de colheita avaliados influenciaram significativamente todas as características avaliadas, enquanto o fator cultivar alterou somente o rendimento de proteína bruta (Tabela 1).

Para todas as características avaliadas, o corte realizado em R2 apresentou os menores rendimentos, diferindo-se de todos os demais estádios de colheita (Tabela 2). Os valores obtidos de massa verde variaram de 19.733 a $30.067 \mathrm{~kg} \mathrm{ha}^{-1}$ sendo considerados satisfatórios quando comparados com os obtidos por outros pesquisadores (Blank \& Rezende, 1994; Botrel \& Rezende, 1999; Rezende et al., 2001) (Tabela 2).

Tabela 1 - Resumo da análise de variância para os valores de massa verde, matéria seca, feno e proteína, obtidos no ensaio cultivares e estádios de colheita para produção de feno de soja, ano agrícola 2001/02, Lavras, MG.

\begin{tabular}{lccccc}
\hline \multirow{2}{*}{ Fontes de Variação } & \multirow{2}{*}{ GL } & \multicolumn{4}{c}{ Quadrados Médios } \\
\cline { 3 - 6 } Bloco & 2 & Massa verde & Matéria seca & Feno & Proteína \\
Cultivar (C) & 1 & $6721333,33^{\mathrm{NS}}$ & $23631,01^{\mathrm{NS}}$ & $32708,29^{\mathrm{NS}}$ & $357258,88^{* *}$ \\
Estádio dcolheita $(\mathbf{E})$ & 4 & $104368666,66^{* *}$ & $20221864,84^{* *}$ & $27988743,93^{* *}$ & $355732,54^{* *}$ \\
C x E & 4 & $2531333,33^{\mathrm{NS}}$ & $246707,57^{\mathrm{NS}}$ & $341460,88^{\mathrm{NS}}$ & $58606,56^{\mathrm{NS}}$ \\
Resíduo & 18 & 2638370,37 & 214336,09 & 296658,47 & 13324,92 \\
\hline $\mathbf{C V}(\%)$ & & $\mathbf{6 , 4 5}$ & $\mathbf{6 , 1 0}$ & $\mathbf{6 , 1 0}$ & $\mathbf{9 , 1 9}$ \\
\hline
\end{tabular}

* Significativo pelo teste $\mathrm{F}$ a $5 \%$ de probabilidade; ** significativo pelo teste $\mathrm{F}$ a $1 \%$ de probabilidade; ${ }^{\text {NS }}$ não significativo pelo teste $\mathrm{F}$. 
Os maiores rendimentos de massa verde foram obtidos no estádio reprodutivo R4, seguidos pelos estádios R5 e R3, que foram semelhantes entre si, sendo os menores rendimentos apresentados no estádio $\mathrm{R} 2$. O estádio R2 apresentou os menores rendimentos para todas as variáveis analisadas.

Observa-se em diversos estudos uma grande influência dos genótipos de soja no rendimento de massa verde, o que não ocorreu no presente trabalho. Oliveira \& Rezende (1987), em ensaios realizados no mesmo local do presente trabalho, utilizando a cultivar de soja Cristalina encontraram rendimentos de massa verde em R2 de $16.431 \mathrm{~kg} \mathrm{ha}^{-1}$, inferiores aos obtidos neste trabalho (19.733 $\mathrm{kg} \mathrm{ha}^{-1}$ ). Menores rendimentos de massa verde foram obtidos nesse trabalho quando se comparam a média do corte R5, de 27.500 $\mathrm{kg} \mathrm{ha}^{-1}$, com as obtidas por Rezende \& Carvalho (1992), trabalhando com 5 cultivares de soja, observaram rendimentos variando entre 28.556 a $34.555 \mathrm{~kg} \mathrm{ha}^{-1}$. Já Rezende \& Takahashi (1990) encontraram rendimentos entre 23.340 e $33.740 \mathrm{~kg} \mathrm{ha}^{-1}$ testando 20 cultivares de soja para produção de feno.

Tabela 2 - Resultados médios para os rendimentos de massa verde, matéria seca, feno e proteína, obtidos no ensaio cultivares e estádios de colheita, ano agrícola 2001/02, Lavras, MG.

\begin{tabular}{ccccc}
\hline Estádio de Colheita & \multicolumn{4}{c}{ Rendimento $\left(\mathbf{k g ~ h a}^{-1}\right)$} \\
\cline { 2 - 5 } & Massa verde & Matéria seca & Feno & Proteína \\
\hline R2 & $19733 \mathrm{~d}$ & $4785 \mathrm{c}$ & $5630 \mathrm{c}$ & $904 \mathrm{c}$ \\
R3 & $26433 \mathrm{~b}$ & $6627 \mathrm{~b}$ & $7797 \mathrm{~b}$ & $1176 \mathrm{~b}$ \\
R4 & $30067 \mathrm{a}$ & $8803 \mathrm{a}$ & $10357 \mathrm{a}$ & $1473 \mathrm{a}$ \\
R5 & $27500 \mathrm{~b}$ & $8760 \mathrm{a}$ & $10306 \mathrm{a}$ & $1499 \mathrm{a}$ \\
R6 & $22167 \mathrm{c}$ & $8949 \mathrm{a}$ & $10528 \mathrm{a}$ & $1227 \mathrm{~b}$ \\
\hline Conquista & $24707 \mathrm{a}$ & $7557 \mathrm{a}$ & $8891 \mathrm{a}$ & $1147 \mathrm{~b}$ \\
Monsoy & $25653 \mathrm{a}$ & $7613 \mathrm{a}$ & $8957 \mathrm{a}$ & $1365 \mathrm{a}$ \\
\hline Média & 25180 & 7585 & 8924 & 1256 \\
\hline
\end{tabular}

* Médias seguidas por letras diferentes minúsculas na coluna diferem entre si pelo teste Scott-Knott a 5\% de probabilidade.

Os rendimentos de matéria seca variaram de 4.785 a $8.949 \mathrm{~kg} \mathrm{ha}^{-1}$, equivalendo aos valores obtidos por outros autores (Rezende et al., 1997b; Rezende et al., 2003), também trabalhando com a cultura da soja para fins forrageiros.

Os rendimentos de matéria seca e feno aumentaram à medida que os cortes foram realizados em estádios mais avançados, sendo as maiores produtividades alcançadas com os cortes nos estádios reprodutivos R4, R5 e R6, que não diferiram entre si. Isso significa que o corte pode ser realizado a partir de R4, sem prejuízos no rendimento de matéria seca ou feno. No caso da produção de massa verde, a partir do estádio R4 ocorre expressiva queda de produtividade.

Segundo observado por Mascarenhas
(1973) o máximo acúmulo de matéria seca na parte aérea da planta de soja ocorre na fase vegetativa, até os 80 dias, com posterior decréscimo acentuado no ganho de peso dos 80 aos 100 dias, como conseqüência da translocação de fotoassimilados para os legumes e sementes. Ainda de acordo com esse mesmo autor, no intervalo de 100 a 140 dias ocorre a maior perda de peso na parte aérea, o que é atribuído principalmente à abscisão foliar. A ausência de perda de peso para matéria seca nos três últimos estádios de colheita (R4, R5 e R6) pode ter ocorrido pela compensação entre a elevação do teor de matéria seca e a perda de folhas que se acentua com o avançar do ciclo, razão pelas quais os rendimentos de matéria seca e feno mostraram-se inalterados nesse período. 
Os rendimentos obtidos, tanto para matéria seca como para a produção feno, mostraram-se em média $3.035 \mathrm{~kg} \mathrm{ha}^{-1}$ e $3.572 \mathrm{~kg}$ $\mathrm{ha}^{-1}$ superiores, respectivamente, aos obtidos, no mesmo local, por Blank \& Rezende (1994), porém, trabalhando com outras cultivares, demonstrando a variabilidade existente entre os materiais genéticos existentes no mercado, além dos fatores climáticos envolvidos. Rezende \& Lima (1984) estudando 38 genótipos de soja, submetidos a corte para a produção de feno, relataram rendimento médio de feno de $5.060 \mathrm{~kg} \mathrm{ha}^{-1}$, inferiores a todos os estádios estudados neste trabalho, possivelmente devido à evolução do potencial produtivo dos novos materiais genéticos avaliados.

Comparando-se os estádios de colheita quanto aos rendimentos de proteína, observa-se que os rendimentos aumentaram até os estádios reprodutivos R4 e R5, que foram estatisticamente iguais. A semelhança entre os rendimentos de proteína para os cortes em $\mathrm{R} 4$ e R5 o corte em R4 como ideal, pela vantagem de possibilitar melhor uso da área com outras culturas em sucessão em razão do menor tempo de permanência da soja no campo. Ressalvando que a possibilidade de um maior intervalo ótimo de corte (entre R4 e R5) é de grande importância para a prática de fenação, considerando as condições de tempo necessário para o processo de secagem.

Visto que o principal propósito da fenação é obter uma forragem desidratada de alta qualidade, observa-se que o alto rendimento de proteína observado no estádio R4, aliado aos altos rendimentos de massa fresca, matéria seca e de feno, indica-nos esse estádio fenológico como o ideal para a prática. Gris et al. (2008) observaram que o estádio de desenvolvimento R4 apresentou a melhor opção de corte para fenação com os maiores teores de nutrientes no feno, independente da cultivar utilizada.

Após o estádio R5, verifica-se uma queda no rendimento de proteína bruta com o corte realizado no estádio R6 com produção semelhante ao corte em R3. O decréscimo nos valores de proteína bruta pode ser explicado pelo efeito de diluição na matéria seca, uma vez que os rendimentos de proteína bruta apresentaram redução brusca neste estádio (R6). Resultados semelhantes foram obtidos por Rezende et al. (2003), na cultura do girassol para a produção de silagem, em que o teor de proteína bruta apresentou este mesmo efeito, ou seja, redução em função do aumento da matéria seca da forragem. Outros autores obtiveram redução nos rendimentos de proteína bruta e outros compostos, acompanhando o processo de maturação de plantas forrageiras (Costa et al. 1993; Bueno, 1999; Gomes, 2003; Leite et al. 1998; Van Soest, 1994). A queda no rendimento de proteína no presente estudo pode, possivelmente, ser explicada não só por diluição de matéria seca, mas também pelo efeito do déficit hídrico entre os estádios R4 e R5, conforme se observa na Figura 1.

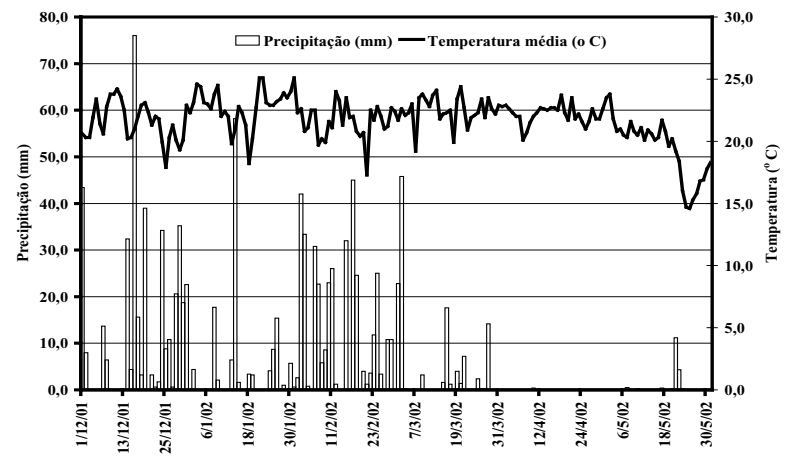

FIGURA 1 - Variação diária da temperatura média do ar e pluviometria de dezembro de 2001 a maio de 2002, UFLA, Lavras - MG. FONTE: Estação Climatológica de Lavras - MG.

Em condições tropicais, os fatores que mais afetam a fixação biológica de nitrogênio são altas temperaturas, estresse hídrico e acidez do solo. $\mathrm{O}$ estresse hídrico influencia negativamente a fixação simbiótica de Nitrogênio (Sugawara et al., 2010), e conseqüentemente o teor de proteína e a produção de 
matéria seca total (Hungria \& Vargas, 2000) Pipolo (2002) observou que a precipitação a variação acentuada do teor de proteína que a temperatura, esse parâmetro altamente correlacionado ao estresse hídrico das plantas.

O rendimento médio de proteína bruta para a cultivar Monsoy 8400 foi superior ao da cultivar Conquista, apresentando cerca de $19 \%$ mais proteína bruta total na matéria seca. Respostas diferenciais de cultivares no rendimento de proteína também foram relatadas em diversos outros trabalhos corroborando com a importância de se estudar e conhecer o efeito de genótipos de soja para uma correta recomendação de cultivares para a fenação (Rezende \& Takahashi, 1990; Rezende et al., 1997a; Rezende et al., 1997b; Botrel et al., 2003).

\section{CONCLUSÕES}

A cultivar de soja Monsoy 8400 apresenta melhor aptidão para a fenação visto seu maior rendimento de proteína bruta que a cultivar Conquista.

Durante a frutificação plena (estádio de desenvolvimento R4), observa-se a época ideal para realizar o corte das plantas de soja visando à fenação de qualidade, independentemente da cultivar utilizada (Monsoy $8400 \mathrm{e}$ Conquista).

\section{REFERÊNCIAS BIBLIOGRÁFICAS}

BLANK, A.F.; REZENDE, P.M. de. Efeito da adubação nitrogenada no plantio sobre produção e características químicas do feno de soja [Glycine Max (L.) Merrill]. Ciência e Prática, Lavras, v.18, n.3, p.258-263, 1994.

BOTREL, E.P; REZENDE, P.M. de; EVANGELISTA, A.R. Avaliação do rendimento forrageiro da soja em quatro sistemas de corte, sucedida por milheto ou milho. Ciência e Agrotecnologia, Lavras, v.27, n.5, p.1122-1129, 2003.
BOTREL, E.P; REZENDE, P.M. de; Maximização da exploração da soja. XV. Efeito de cultivares e épocas da adubação nitrogenada na produção de feno e grãos de rebrota. Ciência e Agrotecnologia, Lavras, v.23, n.1, p.118-123, 1999.

BUENO, M.F. Produção e valor nutritivo dois capins Marandu e Mombaça em diversas épocas de vedação e o uso. 1999. 67p. Dissertação (Mestrado em Zootecnia)

COSTA, N.L. de; OLIVEIRA, J.R.C.; PAULINO, V.T. Efeito do diferimento sobre o rendimento de forragem e composição química de Brachiaria brizantha cv. Marandu em Rondônia. Revista da Sociedade Brasileira de Zootecnia, Viçosa, v.22, n.1, p.495-501, 1993.

DANTAS, A. A. A.; CARVAlHO, L. G.; FERREIRA, E.. Classificação e tendências climáticas em Lavras, MG. Ciência e Agrotecnologia, v. 31, p. 1862/39-1866, 2007.

FEHR, W.R.; CAVINESS, C.E. Stage of soybean development. Ames, Iowa State University, 1977. 11p.

FERREIRA, D. F. SISVAR: um programa para análises e ensino de estatística. Revista Symposium, v. 6, p. 36-41, 2008.

GOMES, V.M. Disponibilidade e valor nutritivo de brachiaria vedada para uso na região semi-árida de Minas Gerais. Lavras: UFLA. 2003. 99p. Dissertação (Mestrado em Zootecnia), Universidade Federal de Lavras.

GRIS, C.F.; REZENDE , P.M.; CARVALHO. E.A.; BOTREL, E.P.; EVANGELISTA, A.R.; ANDRADE, M.J.B. Épocas de corte e cultivares na composição mineral de feno de soja [Glycine max (L.) Merrill]. Ciência e Agrotecnologia, Lavras, v.32, n.2, p.413-419, 2008. 
HUNGRIA, M.; VARGAS, M.A.T. Environmental factors affecting N2 fixation in grain legumes in the tropics, with an emphasis on Brazil. Field Crops Research. v.65, p.151164, 2000.

LEITE, G.G.; COSTA, N.L.; GOMES, A.C. Efeito da época de diferimento sobre a produção e qualidade da forragem de gramíneas na região dos Cerrados do Brasil. Pasturas Tropicales, Cali, v.20, n.1, p.15-22, 1998.

MASCARENHAS, M.M.A. Acúmulo de matéria seca, absorção e distribuição de elementos durante o ciclo vegetativo da soja. Campinas: Instituto Agronômico, 1973. 48p. (Boletim Técnico, 6).

MUNOZ, A.E.; HOLT, E.C.; WEAVER, R.W. Yield and quality of soybean hay as influenced by stage of growth and plant density. Agronomy Journal, Madison, v.75, n.1, p.147-149, 1983.

OLIVEIRA, J.N.S.; REZENDE, P.M.de. Maximização da exploração da soja [Glycine $\max ($ L.) Merrill]. VIII. Efeito da época de corte e adubação nitrogenada na produção de feno e grãos oriundos da rebrota, cv. Cristalina. Ciência e Prática, Lavras, v.11, n.1, p.65-74, 1987.

PIPOLO, A.E. Influência da temperatura sobre as concentrações de proteína e óleo em sementes de soja (Glycine max (L.) Merrill). Piracicaba: ESALQ, 2002. Tese (Doutorado em Fitotecnia).

REZENDE, P.M. de; SILVA, A.G. da; CORTE, E.; BOTREL, E.P. Consórcio Sorgo-Soja. V. Comportamento de híbridos de sorgo e cultivares de soja consorciados na entrelinha no rendimento de forragem. Ciência Rural, Santa Maria. vol.31, n.3, p.369-374, 2001.
REZENDE, P.M. de; ANDRADE, M.J.B. de; RESENDE, G.M. Maximização da exploração da soja [Glycine max (L.) Merrill]. XIII. Efeito da época de corte e da adubação fosfatada na produção de feno e grãos da rebrota. Ciência e Agrotecnologia, Lavras, v.25, n.2, p.299-310, 2001.

REZENDE, P.M. de; BLANK, A.F. e REZENDE, G.M. de. Maximização da exploração da soja [Glycine max (L.) Merrill]. XII. Efeito de sistemas de corte e cultivares na produção de feno. Ensaios e Ciência, Campo Grande, v.1, n.1, p.131-141, 1997a.

REZENDE, P.M. de; CARVALHO E.R. de. Maximização da exploração da soja [Glycine $\max ($ L.) Merrill], X, Efeito de sistemas de corte, adubação nitrogenada no plantio e cultivares na produção de feno, Ciência e Prática, Lavras, v.16, p. 260-269, 1992.

REZENDE, P.M. de; CARVALHO, E.R.de e REZENDE, G.M. de. Maximização da exploração da soja [Glycine max (L.) Merrill]. XI. Efeito de sistemas de corte e da adubação nitrogenada em cobertura na seleção de cultivares para produção de feno. Ciência e Agrotecnologia, Lavras, v.21, n.4, p.457464, $1997 b$.

REZENDE, A.V.; EVANGELISTA, A.R.; SIQUEIRA, G.R. et al. Efeito da densidade de semeadura e composição bromatológica de silagem de girassol (Helianthus annus L.). Lavras - MG, Ciência e Agrotecnologia, Edição especial, p.1672-1678, 2003.

REZENDE, P.M. de; LIMA, L.A. de P. Maximização da exploração da soja [Glycine max (L.) Merrill]. II. Avaliação de genótipos submetidos ao corte, na produção de feno e grãos da rebrota. In: SEMINÁRIO NACIONAL DE PESQUISA DE SOJA, 3, Campinas, 1984. Resumos... Londrina, EMBRAPA-CNPSo, 1984. p.2. 
REZENDE, P.M. de; TAKAHASHI, S. Maximização da exploração da soja [Glycine $\max ($ L.) Merrill]. IX. Efeito do sistema de cortes na seleção de cultivares para produção de feno. Ciência e Prática, Lavras, v.14, p. 44-55, 1990.

RIBEIRO, A.C.; GUIMARÃES, P.T.G.; VICENTE, V.H.A. Recomendações para o uso de corretivos e fertilizantes em Minas Gerais: 5 aproximação. Lavras, 1999. 359p.

SANTOS, O.S. dos, e VIEIRA, C. Crescimento e qualidade nutritiva da planta de soja [Glycine $\max$ (L.) Merrill]. Revista Ceres, Viçosa, v.29, n.161, p.107-115, 1982.
SUGAWARA, M.; CYTRYN, E.J.; SADOWSKY, M.J. Functional Role of Bradyrhizobium japonicum Trehalose Biosynthesis and Metabolism Genes during Physiological Stress and Nodulation. Applied and Environmental Microbiology, v.76, p.1071 1081, 2010.

VAN SOEST, P.J. Nutritional ecology of the ruminant. 2.ed. New York: Cornell University Press, 1994. 476p. 